\title{
The eradication of reactive black 5 dye liquid wastes using Azolla filiculoides aquatic fern as a good and an economical biosorption agent
}

\author{
Davoud Balarak ${ }^{1}$ Tariq J. Al-Musawi² ${ }^{2} \cdot$ Ibrahim A. Mohammed $^{2} \cdot$ Hajar Abasizadeh $^{3}$
}

Received: 18 March 2020 / Accepted: 28 April 2020 / Published online: 4 May 2020

(c) Springer Nature Switzerland AG 2020

\begin{abstract}
Azolla filiculoides (AF) biomass has been tested for its performance as a biosorbent agent toward removing reactive black 5 (RB5) dyes from polluted water. The morphology and structure of the AF was characterized using several advanced techniques. To understand the mechanism of the RB5 biosorption by AF, isotherm, kinetic, and thermodynamic analyses were performed. In addition, the biosorption capacity of AF was tested under various environmental conditions such as solution $\mathrm{pH}(3-11)$, biosorbent dosage $(0.5-8.0 \mathrm{~g} / \mathrm{L})$, contact time (up to $150 \mathrm{~min}$ ), initial pollutant concentration (25-200 mg/L), and solution temperature (273-333 K). The results demonstrated that the biosorption process of RB5 dye onto $\mathrm{AF}$ was quite rapid as the biosorption equilibrium status was attained within $60 \mathrm{~min}$ of reaction initiation. A negative effect on the removal efficiencies was noted with increase in the $\mathrm{pH}$ values from 3 to 11, while the removal efficiency increase by double with the AF dose increase from 0.5 to $2.0 \mathrm{~g} / \mathrm{L}$. The kinetic study revealed that the biosorption trend conformed to the kinetic reaction of the pseudo-second-order. The determined parameters of the thermodynamic studies demonstrated the endothermic and spontaneous of the biosorption nature. Complete compatibility of the biosorption isotherm process with the Langmuir model, with regards to this model the maximum biosorption capacity reached to $41.73 \mathrm{mg} / \mathrm{g}$ under the optimized conditions $(\mathrm{pH}=3$, biosorbent dose $=4 \mathrm{~g} / \mathrm{L}$, initial concentration $=25 \mathrm{mg} / \mathrm{L}$, and room temperature). The biosorption process occurred through both physical interactions and chemical reactions between the pollutant molecules and the biosorbent reaction sites. Our study thus revealed that AF biomass is a cheap and excellent agent with potential for application in the abatement of RB5 dye concentration in wastewater with acidic $\mathrm{pH}$.
\end{abstract}

Keywords Azolla filiculoides · Reactive black 5 dye $\cdot$ Biosorption · Isotherm · Kinetic

\section{Introduction}

Reactive dyes are considered as one of the largest group of organic chemicals that are used in different industries, such as leather, tannery, textiles, cosmetics, food, printing, and plastics [10, 12, 48, 51]. The bright colors, exceptional colorfastness, and the simplicity of use are some of the unique properties of these dyes that encourage their application across several industries [5, 48]. However, reactive dyes can also act as a source of danger if they persist in the environment. For instance, the carcinogenic, mutagenic, and allergic properties of synthetic dyes and their metabolites have been implied to be harmful to human health $[19,27]$. The interference with light penetration and photosynthesis are some other problems that are associated with the presence of dyes in water bodies $[13,25]$.

Tariq J. Al-Musawi, tariq.al-musawi@iu.edu.jo | ${ }^{1}$ Departmentof Environmental Health, Health Promotion Research Center, Zahedan University of Medical Sciences, Zahedan, Iran. ${ }^{2}$ Department of Civil Engineering, Faculty of Engineering, Isra University, Amman,

Jordan. ${ }^{3}$ Department of Environmental Health, Student Research Committee, Zahedan University of Medical Sciences, Zahedan, Iran. 
Therefore, wastewater treatment plants make great efforts toward dye elimination from dye-containing influents as these efforts are essential for the preservation of our environment and public health [19]. Since reactive dyes are highly soluble and less biodegradable, they cannot be treated by the conventional physicochemical methods $[11,29]$. Often, the removal of this type of pollutant requires the application of advanced purification methods. Recently, it was proven that dyes removal through sorption treatment systems such as adsorption, biosorption, or ion exchange is highly effective $[7,18]$. Several advantages such as lower operating cost, lower sensitivity toward toxic pollutants, simplicity of use during the design and operation stages, and the ability to operate at a wide range of pollutant concentrations have been reported for the sorption process [29]. Although several materials such as activated carbon are considered to be effective sorbents in the elimination of dyes, the problems associated with their practical application illustrate the necessity to search for an eco-friendly, low-cost, and abundantly available alternative $[45,54]$. Accordingly, various sorbents have been tested for their sorptive performance toward different types of pollutants [8, 20, 21, 26, 31, 36, 38, 47]. Among these sorbents, several researchers highly recommended fern or aquatic plant biomasses as biosorbents for treating hazardous elements loaded wastewater in the biosorption treatment units $[1,40,46]$. The preference could be due to the good morphological properties, easy availability in huge quantities in the aquatic environment, cost-effectiveness, non-hazardous nature, and efficiency [49]. Recently, aquatic plants were exploited in numerous researches for the elimination of various pollutants [23, $28,58,60]$. In addition, aquatic plants cells consist of brilliant active sites that making them a potential agent for adhering various pollutants from the solutions carrying them [1]. For example, Azolla filiculoides (AF) is a floating aquatic blue-green fern that is widespread across in Asia, Australia and America continents [46, 57]. The ability of rapid colonization and growth is a significant characteristic of AF that has led to serious problems regarding to their agglomeration in the irrigation canals and other hydraulic structures [59]. Moreover, the spreading of this type of aquatic plants in the rivers and other surface water resources raises the question of their disposal as a waste. Thus, the application of such materials in the treatment systems can be considered as an environmental-friendly approach. Therefore, this paper aimed to study the effectiveness of AF as a biosorbent agent for RB5 dye removal. The biosorption efficiency was examined by varying the contact time among the solution $\mathrm{pH}$, initial dye concentration, biosorbent dose, and temperature. In addition, the parameters of isotherm, kinetic, and thermodynamic mechanisms were determined using brilliant models.

\section{Materials and methods}

\subsection{Chemicals}

The stock solutions of RB5 dye (analytical grade, concentration $=1000 \mathrm{ppm}$ ) was provided by the Alvan Sabet Corporation of manufacturing textile dyes and printing paste, Hamadan, Iran. Table 1 lists some properties and chemical structure of RB5 dye. Notably, the working RB5 dye solutions were prepared through dilution and then refrigerated. The prepared RB5 dye solutions were used in the experiments for a maximum period of 7 days. The $\mathrm{pH}$ value of the solutions was fixed by drop wise addition of $0.1 \mathrm{M} \mathrm{HCl}$ and $\mathrm{NaOH}$ solutions.

Table 1 The properties of Reactive Black 5 dye used in this study [10, 29, 53]

\begin{tabular}{lll}
\hline Color index number & 11170 & \\
\hline Molecular weight & $991.8 \mathrm{~g} / \mathrm{mole}$ & \\
$\lambda_{\text {max }}$ &
\end{tabular}




\subsection{Biosorbent preparation}

The required quantity of raw $\mathrm{AF}$ aquatic fern was collected from the Anzali Lagoon, Iran, where it is present in abundance on water surface. The collected fern was oven dried at $60^{\circ} \mathrm{C}$ for 2 days. Thereafter, the dried biomass was crushed and sieved into particles of size 1-2 mm. Next, the dried biomass was soaked in $0.1 \mathrm{M} \mathrm{HCl}$ solution for $5 \mathrm{~h}$ to remove any salts or impurities. Then, the AF biomass was washed with double distilled water until neutral value of $\mathrm{pH}$ was achieved, and then it was dried in the shade. The prepared biosorbent of AF aquatic fern was stored in a stopper glass flask until further analysis. The collection and preparation expenditure of $A F$ aquatic fern in this study was approximately USD 1.5/kg, making this material a relatively cheap biosorbent.

\subsection{Characterization of AF aquatic fern}

The surface area value, morphology, structural characterization, and the brilliant active group's contents of the AF fern biomass were detected by several techniques using appropriate devices. To obtain information about the surface and pore characteristics of $A F$, a sample of this biosorbent was analyzed using the BET- $\mathrm{N}_{2}$ test based on $\mathrm{N}_{2}$ adsorption-desorption isotherms method at $77 \mathrm{~K}$ (ASAP 2000 apparatus). For this test, approximately $130 \mathrm{~g}$ of $A F$ fern biomass sample was degassed under vacuum pressure for $4 \mathrm{~h}$ at $150^{\circ} \mathrm{C}$. Moreover, scanning electron microscope (SEM, Philips XL30 ESEM-TMP) was used to take microscopic images for the AF fern biomass before and after RB5 dye biosorption. In fact, these images provided important information about the variation in the surface morphology of the used AF biomass during biosorption process. The structural properties of the AF fern biomass were examined by $\mathrm{X}$-ray diffraction spectrometer equipped with a generator of copper K-a radiation of wavelength $1.5405 \AA$ (Philips-X'Pert Pro MPD). An $X$-ray fluorescence spectroscopy (XRF) technique (LAB Center XRF-1800) was used to detect the elemental composition of raw AF fern biomass. In addition, the functional group type of the used biosorbent were identified by detecting the FT-IR spectra $\left(400-4000 \mathrm{~cm}^{-1}\right)$ (Nicolet 5700-FT-IRspectroscopy, Thermo Corp., USA).

\subsection{Experiments}

All the experiments of RB5 dye biosorption onto AF fern biomass were conducted in a batch experimental system. Therefore, several 500-mL Erlenmeyer flasks were filled with $100 \mathrm{~mL}$ of RB5 dye solution of specific concentrations. The dye-removal efficiency, in addition to biosorption capacity of AF fern biomass, were examined for diverse experimental conditions such as $\mathrm{pH}$ of $3-11$, doses of $\mathrm{AF}$ fern biomass of $0.5-8.0 \mathrm{~g} / \mathrm{L}$, initial RB5 dye concentration of $25-200 \mathrm{mg} / \mathrm{L}$, and contact time of up to $150 \mathrm{~min}$. These experiments were performed by shaking the mixture of $\mathrm{AF}$ fern biomass-dye solution at $180 \mathrm{rpm}$. At a specific contact time, $3 \mathrm{~mL}$ aqueous samples were suctioned from the reacted solutions with a syringe, centrifuged at $3600 \mathrm{rpm}$ for $5 \mathrm{~min}$, and then tested for RB5 dye residual with UV/ VIS spectrophotometer (DR5000) at a wavelength peak of $597 \mathrm{~nm}$. To ensure high accuracy, the RB5 dye concentration was analyzed thrice for each collected sample, and the averaged value was determined. The performance of AF fern biomass toward RB5 dye was evaluated by calculating the removal efficiency (R\%) (Eq. 1) and the biosorption capacity $\left(q_{t}, \mathrm{mg} / \mathrm{g}\right)$ (Eq. 2$)$ values. Moreover, the equilibrium biosorption capacity represents the biosorption capacity values at the equilibrium condition $\left(q_{e}, \mathrm{mg} / \mathrm{g}\right)$ (Eq. 3) $[41,56]$.

$R \%=\left(1-\frac{C_{t}}{C_{0}}\right) \times 100$

$q_{t}=\left(\frac{C_{0}-C_{t}}{m / V}\right)$

$q_{e}=\left(\frac{C_{o}-C_{e}}{m / V}\right)$

where, $C_{0}, C_{t}$, and $C_{e}$ are the three concentrations of RB5 dye ( $\mathrm{mg} / \mathrm{L})$ : initially, at a specific contact time of biosorption process, and at the equilibrium time, respectively, while $m / V$ represents the AF fern biomass dose in the aqueous solution $(\mathrm{g} / \mathrm{L})$.

The isotherm experiments of RB5 dye biosorption onto $\mathrm{AF}$ fern biomass were conducted using the same experimental procedure as mentioned above but with varying of the temperature from 273 to $333 \mathrm{~K}$. The other experimental parameters were fixed based on the results of the effects study. In addition, the thermodynamic parameters were determined by varying the solution temperature (273-333 K) at an initial RB5 dye concentration of $200 \mathrm{mg} / \mathrm{L}$. The kinetic study was based on the calculations and findings of the effect of initial RB5 dye concentration.

\subsection{Isotherm, kinetic, and thermodynamic models}

\subsubsection{Isotherm models}

The sorption treatment systems involve two important parameters: affinity constants of the targeted pollutants and the maximum capacity of biosorption of the used biosorbent material $[3,32]$. These two parameters are 
essential in designing the sorption system and they can be determined from the isotherm study $[16,42,43]$. Therefore, the experimental equilibrium isotherm curves of $C_{e}$ versus $\mathrm{q}_{\mathrm{e}}$ at different temperatures should be analyzed and modeled using isotherm models. In the present study, the obtained equilibrium data were treated and analyzed via several isotherm models that have been widely used in previous studies for the modeling of the isothermal data and have been much exploited for designing the sorption treatment system $[3,35,40,44]$. These models include Langmuir, Freundlich, and Temkin equations. The Langmuir model describes the mono-layer reaction of the pollutant molecules onto homogeneous sites over the sorbent surface. The linearized mathematical form of Langmuir isotherm model is shown below [61]:

$\frac{C e}{q e}=\frac{1}{q_{m} K_{L}}+\frac{C e}{q_{m}}$

where $\mathrm{K}_{\mathrm{L}}(\mathrm{L} / \mathrm{mg})$ represents the Langmuir sorption constant, which reflects the affinity degree of the active sites for the pollutant molecules under equilibrium condition, and $\mathrm{q}_{\mathrm{m}}(\mathrm{mg} / \mathrm{g})$ is an important parameter in the isotherm studies that displays the maximum sorption capacity of the used sorbent for targeted pollutant molecules.

In addition, Eq. 5 demonstrates the linearized form of Freundlich model [14]. The Freundlich model, unlike the Langmuir model, assumes that the sorbent surface comprises of multi-layered and heterogeneous active sites. This model consists of two parameters: $\mathrm{n}(\mathrm{g} / \mathrm{L})$ and $\mathrm{K}_{\mathrm{f}}((\mathrm{mg} / \mathrm{g})(\mathrm{L} /$ $\left.\mathrm{mg})^{1 / n}\right)$, which represent the sorption intensity and capacity, respectively. In addition, the desirability case of the sorption reactions can be specified when nis greater than 1, as follows:

$\log \mathrm{q}_{\mathrm{e}}=\frac{1}{\mathrm{n}} \log \mathrm{C}_{\mathrm{e}}+\log \mathrm{K}_{\mathrm{f}}$

The Temkin model is a complex isotherm model that counts for the indirect interactions between biosorbent active sites and pollutant molecules. If this model was applicable, then the heat of pollutant molecules biosorption onto the layer of sorption sites of a biosorbent would linearly decrease with an increase in the surface coverage. Since this model ignores the effects of low and high concentrations, it is perfect for application in intermediate pollutant concentrations. Equation 6 represents the linearized form of Temkin isotherm model [24], as given below:

$\mathrm{q}_{\mathrm{e}}=\mathrm{B}_{1} \operatorname{Ln} \mathrm{K}_{\mathrm{T}}+\mathrm{B}_{1} \operatorname{Ln} \mathrm{C}_{\mathrm{e}}$

where $\mathrm{K}_{\mathrm{T}}$ is the equilibrium constant $(\mathrm{L} / \mathrm{mg})$ related to the maximum binding energy and $B_{1}$ is a constant that corresponds to the heat of biosorption.

\subsubsection{Kinetic models}

Kinetic study provides an essential information on the mechanism of the sorption process (i.e., chemical, physical, as well as dominant rate-limiting step and mass transfer) [16]. In this context, it was referred that the design and operation activities for the biosorption treatment process are highly dependent on the results of the kinetic study [37, 40]. Therefore, it is important for kinetic data to be properly analyzed and accurately fitted with the most relevant kinetic equations in order to obtain a mathematical model that accurately represent the treatment system $[33,49]$. In this study, the well-known pseudo-first-order and pseudosecond-order (Eqs. 7 and 8) kinetic equations were used to model the data of evolution curves of Fig. $4 b[34,39]$. Each of these two models expressed the kinetic biosorption reactions under different mechanism that is the physical or chemical process. In addition, to assess the mechanism that dominated and contributed to the control of kinetics capacity as well as to verify whether it is the diffusion is a step that limits the rate, the experimental kinetic data were analyzed using the intra-particle diffusion model (Eq. 9) [15].

$q_{t}=q_{e}\left(1-e^{-k_{1} t}\right)$

$q_{t}=\frac{k_{2} q_{e}^{2} t}{1+k_{2} q_{e} t}$

$\mathrm{q}_{\mathrm{t}}=\mathrm{K}_{\mathrm{p}} \mathrm{t}^{0.5}+\mathrm{C}$

where $k_{1}$ and $k_{2}\left(\min ^{-1}\right)$ are the kinetic rate constants of the pseudo-first-order and pseudo-second-order reactions, respectively; $\mathrm{C}(\mathrm{mg} / \mathrm{g})$ is an important constant that provides information about the thickness of the boundary layer of the used bisorbent; and $\mathrm{K}_{\mathrm{p}}\left(\mathrm{mg} / \mathrm{g} \mathrm{min}^{0.5}\right)$ represents the rate constant of the intra-particle diffusion.

\subsubsection{Thermodynamic models}

The parameters related to thermodynamic, that is enthalpy, variation $\left(\Delta \mathrm{H}^{\circ}\right)$, entropy variation $\left(\Delta \mathrm{S}^{\circ}\right)$, and change in Gibbs free energy $\left(\Delta \mathrm{G}^{\circ}\right)$ were determined from the curve relating the distribution coefficient $(k)$ as a function of different temperature values, using the equations $[2,9]$ :

$\Delta G^{0}=-R T \ln k$

$\ln \mathrm{k}=\frac{\Delta \mathrm{S}^{0}}{R}-\frac{\Delta \mathrm{H}^{0}}{R T}$ 


\section{Result and discussion}

\subsection{Characterization study}

The BET analysis demonstrated that the average surface area of AF fern biomass particles was $36.11 \mathrm{~m}^{2} / \mathrm{g}$. This value is considered superior when compared with the results of similar previous studies that used other types of aquatic plants biomasses rather than AF fern as biosorbents $[1,17,40,50]$. In fact, biosorbents with a large surface area are known as desirable and excellent agents in the treatment processes, because they provide several active sites that are ready to interact with pollutant molecules [10]. In addition, the pore volume of the used AF fern biomass was determined to be $0.113 \mathrm{~cm}^{3} / \mathrm{g}$.

Figure 1 exhibits the high-resolution SEM images of the AF fern biomass before and after the biosorption of RB5 dye. The SEM image of the AF fern biomass before the biosorption process (Fig. 1a) reveals that the surface of this biosorbent is coarse in nature and there are several fragments spread onto its surface. Furthermore, there were several deep pores and big ravines on the wall of this biosorbent material. These morphological properties represent a positive sorptive property for the used material, as these properties indicate that the biosorbent has a high surface area and, therefore, have a large number of reactive locations for capturing the pollutant molecules. Clearly, the morphological properties of AF fern biomass after contacting with RB5 dye (Fig. 1b) were completely changed. Clearly, the surface of AF fern biomass becomes smoother, where several pre-separated fragments are coalesced. In addition, the previously detected pores have almost disappeared. This can be reasoned to theRB5 dye covering on the surface of the AF fern biomass. More important, this phenomenon gives the first impression of the tendency between the biosorbent particles and pollutant molecules.

The FT-IR spectra of AF fern biomass are depicted in Fig. 2. The functional groups observed in the FT-IR
Fig. 1 SEM images of AF fern biomass before (a) and after (b) RB5 dye biosorption
Fig. 2 The FT-IR spectrums of dried AF fern biomass before (a) and after (b) RB5 dye biosorption
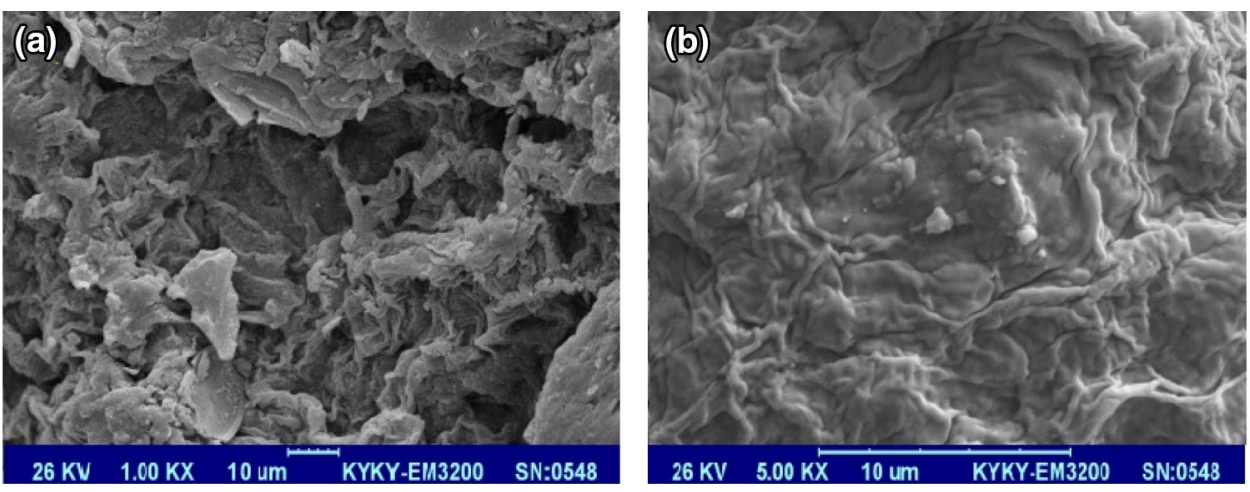

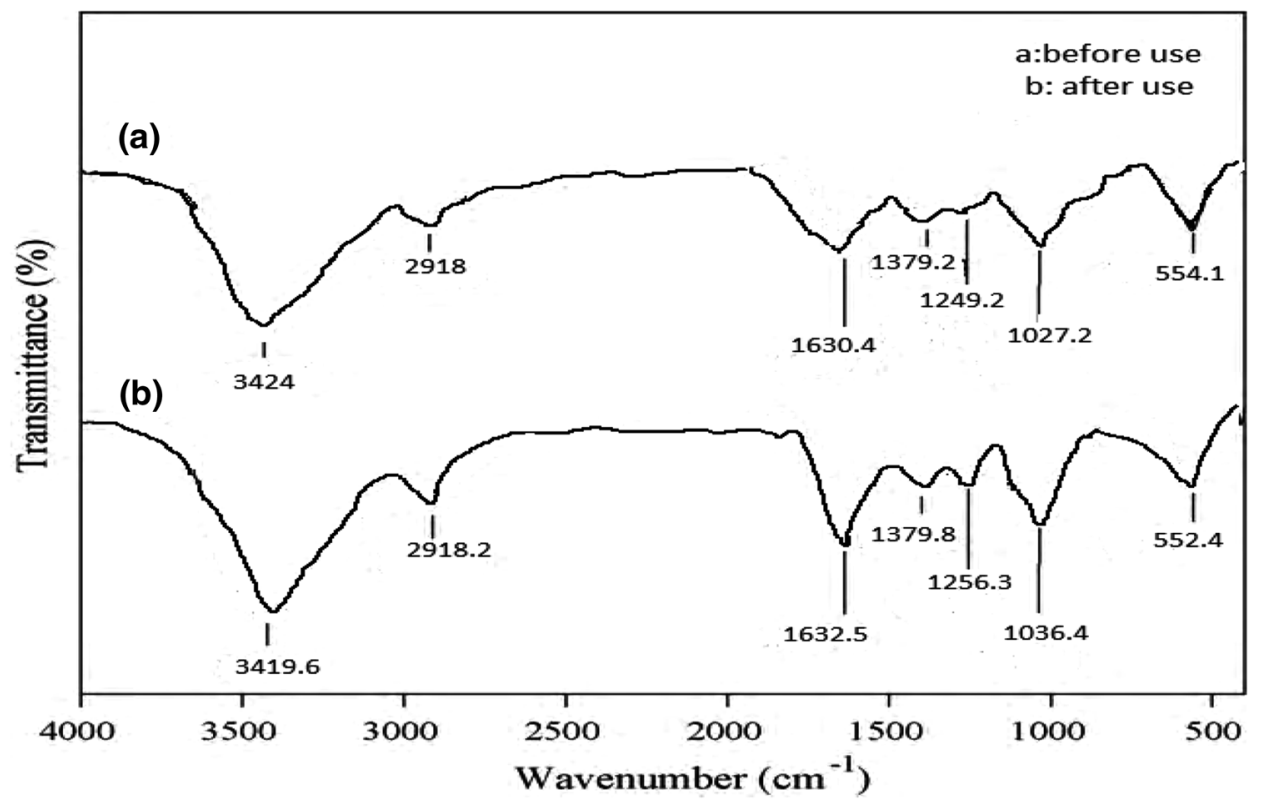

SN Applied Sciences 
spectrum of the AF sample before biosorption include alkenes, esters, alcohol, hydroxyl, and carboxyl. These groups are considered as strong sites for adhering various pollutant molecules from the aqueous solution. The peak detected at $3424 \mathrm{~cm}^{-1}$ corresponded to the $\mathrm{OH}$ stretching vibration mode of $\mathrm{OH}^{-}$and $\mathrm{H}^{+}$bonding functional groups. The peak observed at $2918 \mathrm{~cm}^{-1}$ can be attributed to the presence of aliphatic $\mathrm{C}-\mathrm{H}$ stretching in the structure of AF fern biomass $[1,40]$. The peaks at $1630 \mathrm{~cm}^{-1}$ corresponds to the aromatic-oxygen bond in aromatic ether or stretching of conjugated $\mathrm{C}=\mathrm{C}$ groups. The bands in the wave number range: 1200 and $1380 \mathrm{~cm}^{-1}$ are corresponding to one of the following active groups: (i) $\mathrm{OH}$ bending vibration in the phenolic functional groups, (ii) symmetrical bending of $\mathrm{C}-\mathrm{H}$ bond due to the existence of methyl group, and (iii) or related to the vibration of $-\mathrm{CH}_{2}$ group. The latest group may be overlap with methyl group. In addition, the bands observed around $1000 \mathrm{~cm}^{-1}$ are due to in-plane bending of the aromatic ring $\mathrm{C}-\mathrm{H}$ bond [1]. Comparison between the FT-IR spectrum of AF fern biomass before and after RB5 dye biosorption revealed no big shift in the wave numbers of the functional groups of these two spectrums. In addition, no new peak was noted in the FTIR spectrum after biosorption. This finding suggests that the biosorption process of RB5 dye by the AF

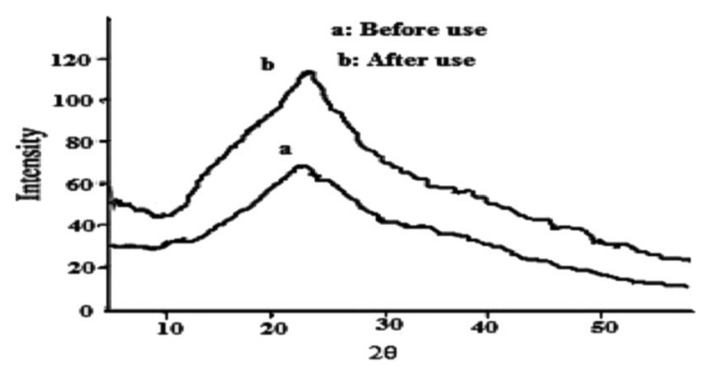

Fig. 3 The XRD patterns of AF fern biomass before (a) and after (b) RB5 dye biosorption fern biomass was physical in nature, where the chemical structure of the active groups of the biosorbent did not change after the biosorption. However, the slight changes that were recorded in the FTIR spectra before and after the biosorption process are due to the interaction between the pollutant molecule and the biosorbent particle.

To gather information about the variation in the crystalline structure of the AF fern biomass particles due to the biosorption of RB5 dye, XRD analysis was performed (Fig. 3). The appearance of the sharp peak at $2 \theta=22.8^{\circ}$ in the XRD pattern of raw AF fern biomass in the figure can be related to the presence of a complex mineral salt in the structure of the fern biomass. Noticeably, this peak in the XRD pattern of the AF fern biomass detected after the RB5 dye biosorption attained a high intensity, which can be attributed to the presentation of RB5 dye molecules due to biosorption onto the active sites of dried AF fern biomass.

XRF analysis (data not shown) revealed that the main elemental compositions of $\mathrm{AF}$ fern biomass were $\mathrm{O}$ (51.28\%), C (32.45\%), H (5.77\%), K (3.9\%), and N (3.5\%). In addition, the following elements were also found in the internal structure of the fern biomass, albeit in lower percent: $\mathrm{Ca}(1.1 \%), \mathrm{Mg}(0.8 \%), \mathrm{Si}(0.5 \%)$, and $\mathrm{P}(0.7 \%)$. The above-mentioned elements are commonly found in natural substances such as surface water aquatic plants.

\subsection{Effects of experimental parameters}

\subsubsection{Initial RB5 dye concentration and contact time}

The biosorption performance of AF fern biomass was tested simultaneously as a function of the RB5 dye concentration (range $25-200 \mathrm{mg} / \mathrm{L}$ ) and contact time (from inception point to $150 \mathrm{~min}$ ). The results are depicted in Fig. 4. The other experimental parameters of $\mathrm{pH}$, biosorbent dosage, and temperature were, in principle, fixed at $4,4 \mathrm{~g} / \mathrm{L}$, and room temperature, respectively. Thus, the dye-removal efficiency decreased with increased initial
Fig. 4 Effects of initial RB5 dye concentrations on its removal efficiency (a), and biosorption capacity (b) using AF fern biomass under the following conditions: contact time of up to $150 \mathrm{~min} ; \mathrm{pH}=3$; biosorbent dose $=4 \mathrm{~g} / \mathrm{L}$, and room temperature
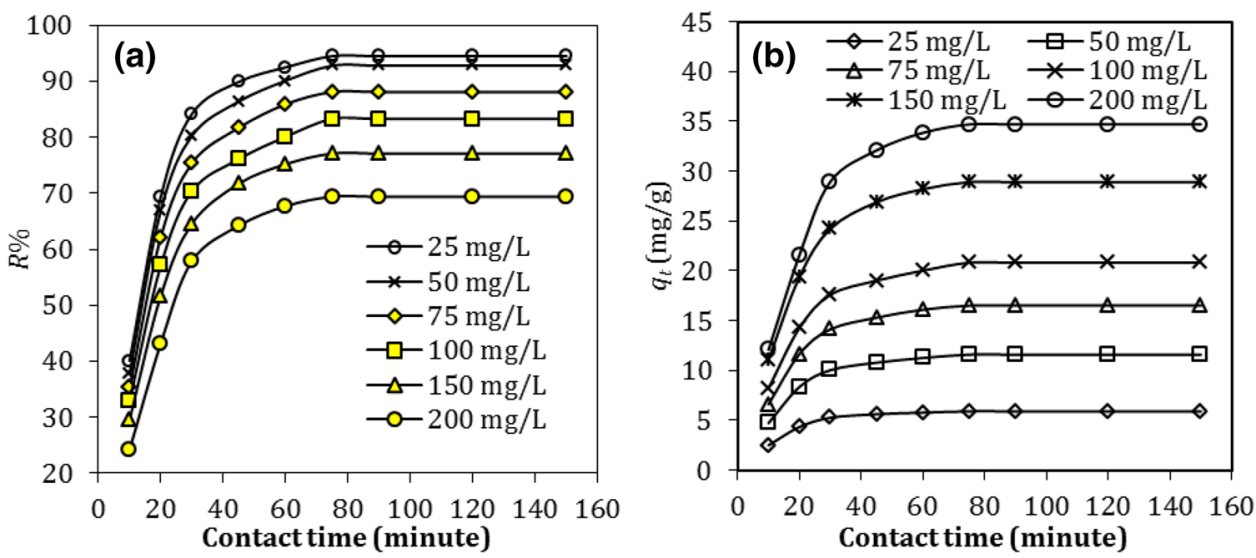
concentration (Fig. 4a) probably because of the biosorbent quantity used in the experiment, which is the same for all initial RB5 dye concentrations. Thus, the number of binding sites was also the same. Therefore, as the concentration of the dye molecules increased while the biosorbent dose in the aqueous solution stayed the same, increased competition was inevitable among the pollutant molecules at the specified binding sites on the biosorbent surface. This trend was also noted by several other researchers, such as the one who discussed the sorption of methyl blue using magnetic carbon nanotube [55]. In addition, the evolution curves of the biosorption capacity (Fig. 4b) demonstrated that the biosorption capacity values remarkably increased with an increase in the initial concentration of RB5 dye. This phenomenon can be reasoned to the high concentration gradients formed at higher pollutant concentrations with the constant biosorbent dosage in this experiment. Therefore, according to the calculations based on Eq. 2, the biosorption capacity values increased with increasing dye concentration. Contrary findings to our results were resulted in the study of Arami et al. [6].

Simultaneously, Fig. $4 \mathrm{~b}$ presents the biosorptive behavior of AF biomass toward RB5 dye removal as a function of the prolonged contact time of up to $160 \mathrm{~min}$. Clearly, the biosorption process reached an equilibrium status at $80 \mathrm{~min}$. In addition, the biosorption process occurred palpably fast, where the greatest part of the biosorption removal occurred in the first $30 \mathrm{~min}$. This phenomenon can be attributed to the fact that, at the initial contact time, the sorption sites were uncovered or unreacted with the RB5 dye molecules. In fact, this is a positive value that can be added for AF biomass to score as a good biosorbent agent for the removal of RB5 dye molecules from wastewater. Notably, the results displayed in Fig. $4 \mathrm{~b}$ were used in the present study as the input data in the modeling process of the kinetic models.

\subsubsection{Effect of $\mathrm{pH}$}

The biosorption process of RB5 dye onto AF fern biomass was studied at a range of $\mathrm{pH} 3-11$, and the results of this test are depicted in Fig. 5 (the other experimental parameters are mentioned in Fig. 5 caption). The solution $\mathrm{pH}$ can affect the removal efficiency of the treatment process via several ways. In general, at different values of solution $\mathrm{pH}$ the pollutant molecule may have different surface charges. From another side, the surface characteristics or the ionization degree of the used sorbent greatly depend on the $\mathrm{pH}$ value of solutions [56]. It can be notice from Fig. 5 that the dye-removal efficiency and uptakes were decreased by increasing the $\mathrm{pH}$. As can be observed, the acidic $\mathrm{pH}$ (especially $\mathrm{pH}=3$ ) was obtained as the most suitable $\mathrm{pH}$ for the maximum RB5-removal efficiency, which is in agreement

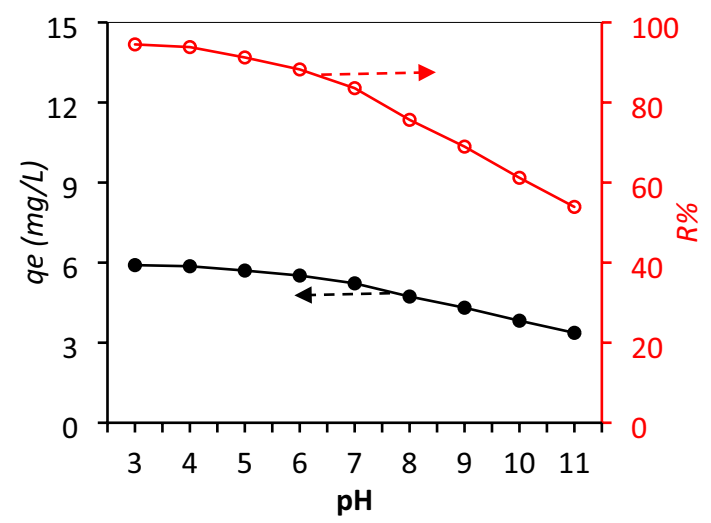

Fig. 5 The effect of $\mathrm{pH}$ on the AF fern biomass performance toward RB5 dye biosorption (contact time $=75 \mathrm{~min}$, initial dye concentration $=25 \mathrm{mg} / \mathrm{L}$, biosorbent dose $=4 \mathrm{~g} / \mathrm{L}$ )

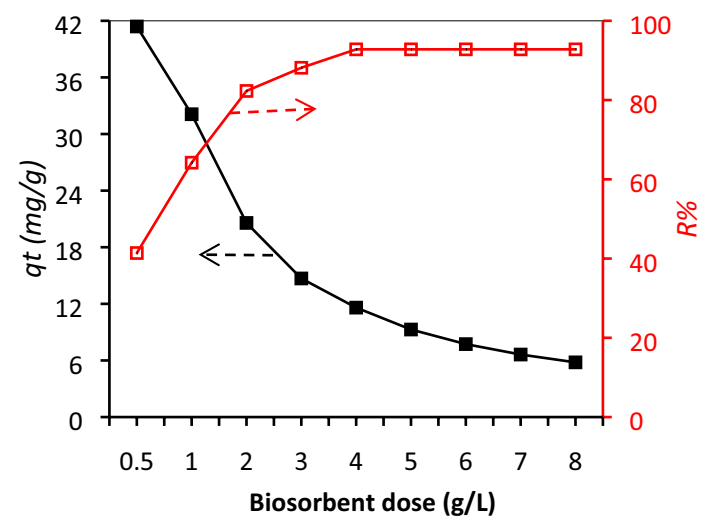

Fig. 6 The effect of AF fern biomass doses on its biosorption efficiency for RB5 dye (contact time $=75 \mathrm{~min}, \mathrm{pH}=3$, RB5 dye concentration $=50 \mathrm{mg} / \mathrm{L}$ )

with the report by other studies $[28,57]$. An increase in the electrostatic attraction between pollutant molecules and the sorption sites on the biosorbent surface at lower $\mathrm{pH}$ was expressed as a reason for this event by various studies [56].

\subsubsection{Effect of biosorbent dose}

The effect of biosorbent dosages for RB5 dye removal was performed using AF biomass dosages of $0.5-8 \mathrm{~g} / \mathrm{L}$ and at the optimum $\mathrm{pH}$ and dye concentration, and the results are shown in Fig. 6. The RB5-removal efficiency was 41.40 and $92.81 \%$ for the biosorbent dosages of 0.5 and $8.0 \mathrm{~g} / \mathrm{L}$, respectively; it highlights that the dye-removal efficiency was increased by increasing the AF biomass dosage. It is apparent that the further increase in the AF biomass dosage had a reverse effect on the dye biosorption capacity. Moreover, an increase in the AF biomass dosage had a reverse effect on the dye biosorption capacity. This finding 
Table 2 The obtained parameters and the coefficient of regression of the applied isotherm models of the RB5 dye biosorption onto AF fern biomass at temperatures: $273-333 \mathrm{~K}$

\begin{tabular}{|c|c|c|c|c|c|c|c|c|c|}
\hline \multirow{2}{*}{$\begin{array}{l}\text { Model } \\
\text { Parameter }\end{array}$} & \multicolumn{3}{|l|}{ Langmuir } & \multicolumn{3}{|c|}{ Freundlich } & \multicolumn{3}{|l|}{ Temkin } \\
\hline & $\mathrm{q}_{\mathrm{m}}(\mathrm{mg} / \mathrm{g})$ & $\mathrm{K}_{\mathrm{L}}(\mathrm{L} / \mathrm{mg})$ & $\mathrm{R}^{2}$ & $\mathrm{n}$ & $\begin{array}{l}\mathrm{K}_{\mathrm{f}}((\mathrm{mg} / \mathrm{g}) \\
\left.(\mathrm{L} / \mathrm{mg})^{1 / \mathrm{n}}\right)\end{array}$ & $\mathrm{R}^{2}$ & $\mathrm{~B}_{1}$ & $\mathrm{~K}_{\mathrm{T}}$ & $\mathrm{R}^{2}$ \\
\hline 273 & 33.141 & 0.084 & 0.961 & 1.951 & 12.420 & 0.885 & 19.411 & 0.120 & 0.829 \\
\hline 293 & 35.632 & 0.069 & 0.978 & 2.460 & 10.281 & 0.864 & 26.592 & 0.470 & 0.796 \\
\hline 313 & 38.483 & 0.048 & 0.986 & 2.831 & 7.832 & 0.902 & 31.111 & 0.681 & 0.845 \\
\hline 333 & 41.731 & 0.027 & 0.992 & 3.570 & 4.964 & 0.927 & 36.220 & 0.930 & 0.861 \\
\hline
\end{tabular}

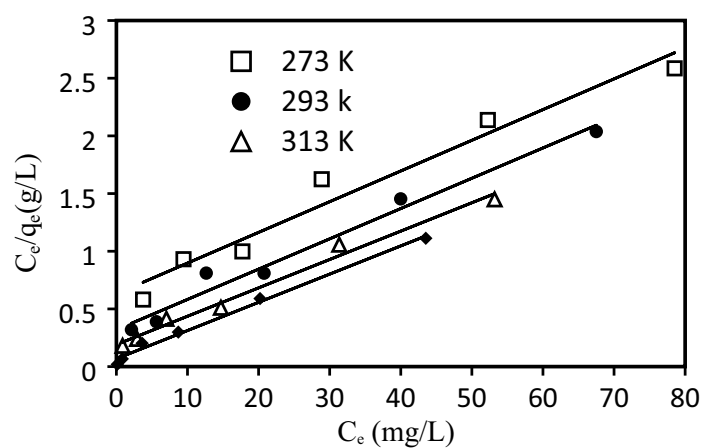

Fig. 7 Langmuir model plots with the experimental isotherm data of the RB5 dye biosorption onto AF fern biomass

thoroughly agree with the findings of $[4,30,52]$ studies. The availability of greater biosorption site was announced for increasing the dye-removal efficiency and the presence of unsaturated biosorption sites was attributed the reason for decreased dye biosorption efficiency $[22,53]$. In addition, the addition in the AF biomass dose greater than $4 \mathrm{~g} / \mathrm{L}$ has no or minimal improvement on the removal efficiencies of RB5 dyes. The reason behind this behavior is the agglomeration of some biosorbent particles in the aqueous solution at high doses, owing to the aggregation of the available sorption sites of the AF biomass used.

\subsection{Isotherm studies}

The results of the parameters of the three applied models with their corresponding regression of coefficient $\left(R^{2}\right)$ values are listed in Table 2. The determined $R^{2}$ values of the
Langmuir model were estimated to be $>0.995$ at different temperatures. In addition, comparison of the results with those of other two models revealed that the Langhamir isotherm was more accurate in representing the experimental data. These results demonstrate a single layer of reaction of RB5 dye molecules onto the homogeneous surfaces of AF fern biomass. Figure 7 was prepared in accordance with the linear plot of the Langhamir isotherm results presented in Table 2 and the experimental isotherm data. Notably, the obtained maximum capacities of AF fern biomass for RB5 dye biosorption was found to be 33.14 , $35.63,38.48$, and $41.73 \mathrm{mg} / \mathrm{g}$ at temperatures 273,293 , 313 , and $333 \mathrm{~K}$, respectively. On the other side, the $n$ values of Freundlich model were determined to be $>1$, which is considered as a physical biosorption for RB5 dye reaction onto the active sites of AF fern biomass [3].

\subsection{Kinetic studies}

The results of the parameters of each kinetic model are given in Table 3. These results indicate that, the kinetic model of the pseudo-second-order was best-fit with the kinetic data wherein the highest $R^{2}$ values were determined (also see Fig. 8, which shows high regression between the theoretical data of the second-order-kinetic model and the kinetic data). Since the assumption of the mechanism of second-order kinetic model that is based on chemical biosorption in addition to the isotherm study that exhibited physical biosorption, it can be deduced that the major reaction of RB5 dye molecules on the surface of the AF fern biomass particles occurred through both chemical and physical/ion exchange reactions.
Table 3 The values of kinetic studies obtained for RB5 removal with dried $A F$

\begin{tabular}{|c|c|c|c|c|c|c|c|c|c|}
\hline \multirow{2}{*}{$\begin{array}{l}\text { Model } \\
\text { Initial } \\
\text { conc. } \\
\text { (mg/L) }\end{array}$} & \multicolumn{3}{|c|}{ Pseudo-first-order } & \multicolumn{3}{|c|}{ Pseudo-second-order } & \multicolumn{3}{|c|}{ Intra-particle diffusion } \\
\hline & $\begin{array}{l}\mathrm{K}_{1} \\
\left(\mathrm{~min}^{-1}\right)\end{array}$ & $\mathrm{R}^{2}$ & $\begin{array}{l}\mathrm{q}_{\mathrm{e}} \\
(\mathrm{mg} / \mathrm{g})\end{array}$ & $\begin{array}{l}\mathrm{k}_{2} \\
\left(\min ^{-1}\right)\end{array}$ & $\mathrm{R}^{2}$ & $\begin{array}{l}\mathrm{q}_{\mathrm{e}} \\
(\mathrm{mg} / \mathrm{g})\end{array}$ & $\begin{array}{l}\mathrm{K}_{\mathrm{p}} \\
\left(\mathrm{mg} / \mathrm{g} \min ^{0.5}\right)\end{array}$ & $\begin{array}{l}\mathrm{C} \\
(\mathrm{mg} / \mathrm{g})\end{array}$ & $\mathrm{R}^{2}$ \\
\hline 25 & 0.074 & 0.924 & 4.540 & 0.0054 & 0.995 & 6.411 & 0.545 & 3.450 & 0.845 \\
\hline 50 & 0.056 & 0.941 & 9.850 & 0.0096 & 0.997 & 11.920 & 0.712 & 2.173 & 0.905 \\
\hline 100 & 0.034 & 0.952 & 17.450 & 0.0741 & 0.999 & 21.150 & 1.040 & 4.251 & 0.842 \\
\hline 200 & 0.021 & 0.933 & 24.640 & 0.0461 & 0.998 & 33.540 & 1.380 & 1.971 & 0.894 \\
\hline
\end{tabular}




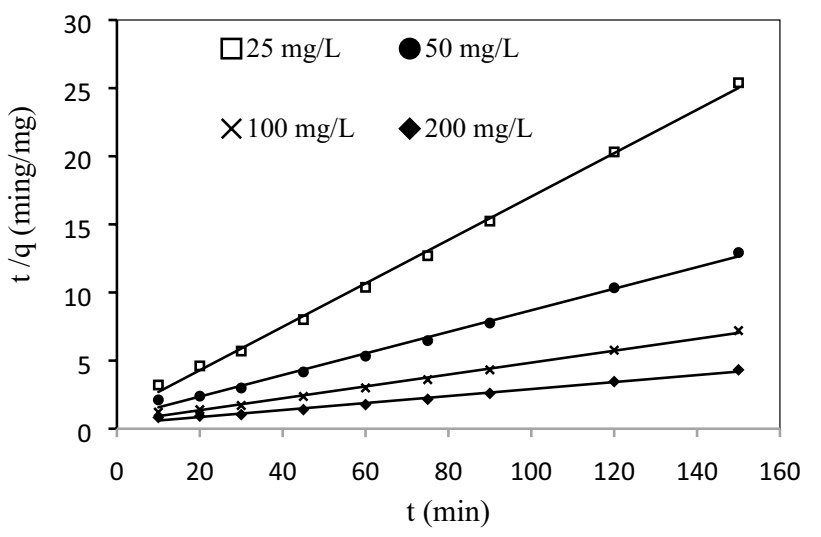

Fig. 8 Pseudo-second-order kinetic plots for the experimental data of RB5 biosorption onto AF fern biomass

Table 4 Thermodynamics parameters for RB5 biosorption on AF biomass

\begin{tabular}{llll}
\hline $\mathrm{T}(\mathrm{K})$ & $\Delta \mathrm{G}^{\circ}(\mathrm{kJ} / \mathrm{mol})$ & $\Delta \mathrm{H}^{\circ}(\mathrm{kJ} / \mathrm{mol})$ & $\Delta \mathrm{S}^{\circ}(\mathrm{J} / \mathrm{mol} \mathrm{k})$ \\
\hline 273 & -2.15 & 013.86 & 0.042 \\
293 & -1.70 & & \\
313 & -0.935 & & \\
333 & -0.281 & & \\
\hline
\end{tabular}

\subsection{Thermodynamics studies}

The variation of temperature between 273 and $333 \mathrm{~K}$ were considered to comprehend the effect of this parameter on the biosorption of RB5. The result obtained from this section of study clarified the negative effect of it on the biosorption of RB5 onto AF biomass. The estimation of $\Delta \mathrm{H}^{\circ}$ and $\Delta \mathrm{S}^{\circ}$ were conducted through the slope and $y$-intercept of the straight line acquired by plotting $\mathrm{Ln} \mathrm{K}$ against $1 / \mathrm{T}(\mathrm{K})$. The values calculated for $\Delta \mathrm{H}^{\circ}, \Delta \mathrm{S}^{\circ}$, and $\Delta \mathrm{G}^{0}$ are given in Table 4 . The positive value of $\Delta \mathrm{H}^{\circ}$ is indicative of the endothermic biosorption nature of the RB5 onto the AF biomass. The negative value obtained for $\Delta G^{0}$, at various temperatures, portends the viability and spontaneity of the studied process $[6,55]$. Increasing the $\Delta G^{\circ}$ by raising the temperature hints the favorability of biosorption at higher temperatures. Additionally, the positive value of $\Delta S^{\circ}$ manifests the inclination of AF biomass for RB5 as well as authenticates the increase in the randomness at the solid-solution interface during the studied process.

\section{Conclusion}

The biosorption of RB5 dye using AF biomass was perused in this study. The results obtained demonstrated the dependency of the biosorption of RB5 dye on the parameters studied, such as the initial RB5 dye concentration, contact time, and temperature. Moreover, it was recognized that the highest RB5 dye removal efficiency for the dye concentration of $25 \mathrm{mg} / \mathrm{L}$ was achieved using the biomass dosage of $4 \mathrm{~g} / \mathrm{L}$. Isotherm studies admitted the aptness of the Langmuir model for the elucidation of equilibrium biosorption data; this aspect ascertains that the studied process was of the type of monolayer biosorption onto a homogenous surface. In addition, with regards to the results, the biosorption capacity of the prepared biosorbent was $35.63 \mathrm{mg} / \mathrm{g}$ at the room temperature $\left(298^{\circ} \mathrm{K}\right)$. In addition, the most effective model for representing the biosorption kinetic was accredited to be the pseudo-second-order model, while the intra-particle diffusion did not act as the only rate controlling step of the biosorption process. According to the thermodynamic studies, the negative value were obtained for $\Delta \mathrm{G}^{0}$, while the values of $\Delta \mathrm{H}^{0}$ were positive; these results support the fact that the RB5 dye biosorption on AF biomass has the spontaneous and endothermic nature. Thus, we found that the AF fern biomass can be applied as an effective biosorbent for the lowering of RB5 dye concentration in polluted water and wastewater effluents.

Acknowledgements The researchers are greatly indebted to the Zahedan University of Medical Sciences (Iran) for their financial support. Moreover, the researchers appreciate the support extended by the Isra University (Jordan). A special thanks to GlobalEdico Company for their help in improving the English language level of this paper.

\section{Compliance with ethical standards}

Conflict of interest On behalf of all authors, the corresponding author states that there is no conflict of interest.

\section{References}

1. Abdelkareem H, Alwared A, Al-Musawi TJ, Brouers F (2019) A comparative study for the identification of superior biomass facilitating biosorption of copper and lead ions: a single alga or a mixture of algae. Int J Environ Res 13(3):533-546

2. Akar T, Ozcan AS, Tunali S, Ozcan A (2008) Biosorption of a textile dye (Acid Blue 40) by cone biomass of Thuja orientalis: estimation of equilibrium, thermodynamic and kinetic parameters. Biores Technol 99(8):3057-3065

3. Aljeboree AM, Alshirifi AN, Alkaim AF (2017) Kinetics and equilibrium study for the adsorption of textile dyes on coconut shell activated carbon. Arab J Chem 10:S3381-\$3393

4. Amin NK (2008) Removal of reactive dye from aqueous solutions by adsorption onto activated carbons prepared from sugarcane bagasse pith. Desalination 223(1-3):152-161

5. Amin NK (2009) Removal of direct blue-106 dye from aqueous solution using new activated carbons developed from pomegranate peel: adsorption equilibrium and kinetics. J Hazard Mater 165(1-3):52-62 
6. Arami M, Limaee NY, Mahmoodi NM, Tabrizi NS (2005) Removal of dyes from colored textile wastewater by orange peel adsorbent: equilibrium and kinetic studies. J Colloid Interface Sci 288:371-376

7. Arami M, Limaee NY, Mahmoodi NM (2008) Evaluation of the adsorption kinetics and equilibrium for the potential removal of acid dyes using a biosorbent. Chem Eng J 139(1):2-10

8. Arica MY, Bayramoğlu G (2007) Biosorption of Reactive Red120 dye from aqueous solution by native and modified fungus biomass preparations of Lentinus sajor-caju. J Hazard Mater 149(2):499-507

9. Balarak D, Mostafapour FK (2018) Adsorption of acid red 66 dye from aqueous solution by heat-treated rice husk. Res J Chem Environ 22(12):80-84

10. Balarak D, Mostafapour FK, Joghataei A (2016) Adsorption of acid blue 225 dye by multi walled carbon nanotubes: determination of equilibrium and kinetics parameters. Der Pharma Chem 8(8):138-145

11. Balarak D, Azarpira H (2016) Biosorption of acid orang 7 using dried Cyperus rotundus: isotherm studies and error functions. Int J ChemTech Res 9(9):543-549

12. Balarak D, Jaafari J, Hassani G, Mahdavi Y, Tyagi I, Agarwal S, Gupta VK (2015) The use of low-cost adsorbent (Canola residues) for the adsorption of methylene blue from aqueous solution: isotherm, kinetic and thermodynamic studies. Colloids Interface Sci Commun 7:16-19

13. Balarak D, Mahdavi Y, Bazrafshan E, Mahvi AH (2016) Kinetic, isotherms and thermodynamic modeling for adsorption of acid blue 92 from aqueous solution by modified azolla filiculoides. Fresenius Environ Bull 25(5):1321-1330

14. Belessi V, Romanos G, Boukos N, Lambropoulou D, Trapalis C (2009) Removal of Reactive Red 195 from aqueous solutions by adsorption on the surface of $\mathrm{TiO}_{2}$ nanoparticles. J Hazard Mater 2009(170):836-844

15. Boparai HK, Joseph M, O'Carroll DM (2011) Kinetics and thermodynamics of cadmium ion removal by adsorption onto nanozerovalent iron particles. J Hazard Mater 186(1):458-465

16. Brouers F, Al-Musawi TJ (2018) Brouers-Sotolongo fractal kinetics versus fractional derivative kinetics: a new strategy to analyze the pollutants sorption kinetics in porous materials. J Hazard Mater 350:162-168

17. Brouers F, Al-Musawi TJ (2015) On the optimal use of isotherm models for the characterization of biosorption of lead onto algae. J Mol Liq 212:46-51

18. Choudhary P, Singh J, Subramanian S (2015) Biosorption of acidic dye from an aqueous solution by amarine bacterium, Planococcussp. Int J ChemTech Res 8(4):1763-1768

19. Constantin M, Asmarandei I, Harabagiu V, Ghimici L, Ascenzi P, Fundueanu G (2013) Removal of anionic dyes from aqueous solutions by an ion-exchanger based on pullulan microspheres. Carbohyd Polym 91(1):74-84

20. Daneshvar E, Kousha M, Sohrabi MS, Khataee A, Converti A (2012) Biosorption of three acid dyes by the brown macroalga Stoechospermum marginatum: isotherm, kinetic and thermodynamic studies. Chem Eng J 195-196:297-306

21. Daniel S, Shabudeen PS (2015) Acid dye removal by using modified activated carbon encapsulated with nano particles. Int J ChemTech Res 8(2):845-885

22. Deniz F, Karaman S (2011) Removal of Basic Red 46 dye from aqueous solution by pine tree leaves. Chem Eng J 170(1):67-74

23. Diyanati RA, Yousefi Z, Cherati JY (2013) The ability of Azolla and lemna minor biomass for adsorption of phenol from aqueous solutions. J Mazandaran Univ Med Sci 23(106):17-23

24. Diyanati RA, Yousefi Z, Cherati JY (2013) Adsorption of phenol by modified azolla from aqueous solution. J Mazandaran Univ Med Sci 22(2):13-21
25. Dotto GL, Moura JM, Cadaval TRS, Pinto LA (2013) Application of chitosan films for the removal of food dyes from aqueous solutions by adsorption. Chem Eng J 214:8-16

26. El Ashtoukhy SZ (2009) Loofa egyptiaca as a novel adsorbent for removal of direct blue dye from aqueous solution. J Environ Manag 90(8):2755-2761

27. Erdem E, Colgecen G, Donat R (2005) The removal of textile dyes by diatomite earth. J Colloid Interface Sci 282:314-319

28. Forni C, Cascone A, Fiori M, Migliore L (2002) Sulphadimethoxine and Azolla filiculoides Lam.: a model for drug remediation. Water Res 36(13):3398-3403

29. Galán J, Rodríguez A, Gómez JM, Allen SJ, Walker GM (2013) Reactive dye adsorption onto a novel mesoporous carbon. Chem Eng J 219:62-68

30. Gök Ö, Özcan AS, Özcan A (2010) Adsorption behavior of a textile dye of Reactive Blue 19 from aqueous solutions onto modified bentonite. Appl Surf Sci 256(17):5439-5443

31. Gong R, Sun Y, Chen J, Liu H, Yang C (2005) Effect of chemical modification on dyeadsorption capacity of peanut hull. Dyes Pigm 67:175-181

32. Gupta VK, Ali I, Mohan D (2003) Equilibrium uptake and sorption dynamics for the removal of basic dye (basic red) using low-cost adsorbents. J Colloid Interface Sci 265(2):257-264

33. Hameed BH, Ahmad AA, Aziz A (2007) Isotherms, kinetics and thermodynamics of acid dye adsorption on activated palm ash. Chem Eng J 133(1-3):195-203

34. Ho YS, Mckay G (2000) The kinetics of sorption of divalent metal ions onto sphagnum moss peat. Water Res 34(3):735-742

35. Hossain MA, Ngo HH, Guo WS, Setiadi T (2012) Adsorption and desorption of copper(II) ions onto garden grass. J Bioresour Technol 121:386-395

36. Jirekar DB, Pramila G, Farooqui M (2014) Kinetics and isotherm studies on crystal violet dye adsorption onto black gram seed husk. Int J ChemTech Res 7(1):427-443

37. Khodadadi M, Al-Musawi TJ, Kamranifar M, Saghi MH, Panahi $\mathrm{AH}$ (2019) A comparative study of using barberry stem powder and ash as adsorbents for adsorption of humic acid. Environ Sci Pollut Res 26:26159-26169

38. Kyzas GZ, Lazaridis NK, Mitropoulos AC (2012) Removal of dyes from aqueous solutions with untreated coffee residues as potential low-cost adsorbents: equilibrium, reuse and thermodynamic approach. Chem Eng J 189-190:148-159

39. Lagergren S (1898) About the theory of so-called adsorption of soluble substances. Kungliga Svenska Vetenskapsakademiens Handlingar 24:1-39 (in Swedish)

40. Mohammed AA, Najim AA, Al-Musawi TJ, Alwared Al (2019) Adsorptive performance of a mixture of three nonliving algae classes for nickel remediation in synthesized wastewater. J Environ Health Sci and Eng 17(2):529-538

41. Mohammed AA, Al-Musawi TJ, Kareem SL, Zarrabi M, AlMa'abreh AM (2020) Simultaneous adsorption of tetracycline, amoxicillin, and ciprofloxacin by pistachio shell powder coated with zinc oxide nanoparticles. Arab J Chem. https://doi. org/10.1016/j.arabjc.2019.10.010

42. Mohan D, Singh KP, Singh G, Kumar K (2002) Removal of dyes from wastewater using flyash, a low-cost adsorbent. Ind Eng Chem Res 41(15):3688-3695

43. Mohseni-Bandpi A, Al-Musawi TJ, Ghahramani E, Zarrabi M, Mohebi S, Vahed SA (2016) Improvement of zeolite adsorption capacity for cephalexin by coating with magnetic $\mathrm{Fe}_{3} \mathrm{O}_{4}$ nanoparticles. J Mol Liq 218:615-624

44. Nasseh N, Al-Musawi TJ, Miri MR, Rodriguez-Couto S, Hossein Panahi A (2020) A comprehensive study on the application of FeNi3@SiO2@ZnO magnetic nanocomposites as a novel photocatalyst for degradation of tamoxifen in the presence of simulated sunlight. Envrion Pollut 261:114127 
45. Ozcan A, Ozcan AS (2005) Adsorption of acid red 57 from aqueous solutions onto surfactant modified sepiolite. J Hazard Mater 125:252-259

46. Padmesh TVN, Vijayaraghavan K, Sekaran G, Velan M (2005) Batch and column studies on biosorption of acid dyes on fresh water macro alga Azolla filiculoides. J Hazard Mater 125(1-3):121-129

47. Ponnusami V, Vikram S, Srivastava SN (2008) Guava (Psidium guajava) leaf powder: novel adsorbent for removal of methylene blue from aqueous solutions. J Hazard Mater 152(1):276-286

48. Ponnusami V, Krithika V, Madhuram R, Srivastava SN (2007) Biosorption of reactive dye using acid-treated rice husk: factorial design analysis. J Hazard Mater 142(1-2):397-403

49. Sulaymon AH, Mohammed AA, Al-Musawi TJ (2013) Column biosorption of lead, cadmium, copper, and arsenic ions onto algae. J Bioprocess Biotechnol 3:1-7. https://doi. org/10.4172/2155-9821.1000128

50. Sulaymon AH, Mohammed AA, Al-Musawi TJ (2014) Comparative study of removal of cadmium (II) and chromium (III) ions from aqueous solution using low-cost biosorbent, 2014. Int J Chem React Eng 12(1):1-10

51. Tan C-Y, Li G, Lu XQ, Chen ZI (2010) Biosorption of basic orange using dried A. filiculoides. Ecol Eng 36(10):1333-1340

52. Tor A, Cengeloglu Y (2006) Removal of Congo red from aqueous solution by adsorption onto acid activated red mud. J Hazard Mater 138(2):409-415

53. Tunç Ö, Tanc H, Aksu Z (2009) Potential use of cotton plant wastes for the removal of Remazol Black $B$ reactive dye. J Hazard Mater 163(1):187-198

54. Wang L, Li J (2013) Adsorption of C.I. Reactive Red 228 dye from aqueous solution by modified cellulose from flax shive: kinetics, equilibrium, and thermodynamics. Ind Crops Prod 42:153-158
55. Wang S, Gao Q, Luo W, Xu J, Zhou C, Xia H (2013) Removal of methyl blue from aqueous solution by magnetic carbon nanotube. Water Sci Technol 68(3):665-673

56. Yazdanbakhsh M, Tavakkoli H, Hosseini SM (2011) Characterization and evaluation catalytic efficiency of $\mathrm{NiO} 3$ nanopowders in removal of reactive blue 5 from aqueous solution. Desalination 281:388-395

57. Zazouli MA, Mahvi AH, Dobaradaran S, Barafrashtehpour M, Mahdavi Y (2014) Adsorption of fluoride from aqueous solution by modified Azolla filiculoides. Fluoride 47(4):349-358

58. Zazouli MA, Yazdani J, Balarak D, Ebrahimi M, Mahdavi Y (2013) Removal of acid blue 113 from aqueous solution by canola. J Mazandaran Univ Med Sci 23(2):73-81

59. Zazouli MA, Mahdavi Y, Bazrafshan E (2014) Phytodegradation potential of bisphenol A from aqueous solution by Azolla filiculoides. J Iran J Environ Health Sci Eng 10:14-20

60. Zhang X, Lin AJ, Zhao FJ, Xu GZ, Duan GL, Zhu YG (2008) Arsenic accumulation by the aquatic fern Azolla: comparison of arsenate uptake, speciation and efflux by A. caroliniana and A. filiculoides. Environ Pollut 156(3):1149-1155

61. Zulfikar MA, Setiyanto H (2013) Study of the adsorption kinetics and thermodynamic for the removal of congo red from aqueous solution using powdered eggshell. Int J ChemTech Res 5(4):1671-1678

Publisher's Note Springer Nature remains neutral with regard to jurisdictional claims in published maps and institutional affiliations. 